\title{
Malignant mesothelioma of the pleura in Barrow-in-Furness
}

\author{
J. R. EDGE AND S. L. CHOUDHURY
}

From High Carley and North Lonsdale Hospitals, Barrow-in-Furness, Cumbria, UK

Edge, J. R. and Choudhury, S. L. (1978). Thorax, 33, 26-30. Malignant mesothelioma of the pleura in Barrow-in-Furness. Fifty cases of malignant pleural mesothelioma (47 men and 3 women) have been diagnosed during the period 1966-76 in Barrow-in-Furness, all of them histologically proved and accepted by the Pneumoconiosis Panel. At the time of writing only three survive.

There was a history of industrial exposure to asbestos in all $47 \mathrm{men}$, who had worked in various trades in the shipyard, as had one of the women. One of the women was married to a shipyard plumber, who may have brought home asbestos dust on his clothes. Only one patient, a housewife, aged 28 at diagnosis, had no known asbestos contact.

The asbestos content of the lungs has been measured in the last 20 cases, in 18 of whom it was found to be substantially greater than the accepted levels for the general population. In a small number studied by electron microscopy, the predominant fibre was crocidolite.

A positive histological diagnosis was achieved in 39 subjects during life in the expectation of securing industrial compensation, but, in spite of this, less than half of the dependants are currently receiving payments.

Metastases, though never clinically apparent, were frequent at necropsy.

Barrow-in-Furness has a population of 64000 . Ship construction is the principal industry, employing some 7000 men. In the immediate post-war years a number of captured German ships were refitted in Barrow. This involved the removal of large amounts of crocidolite, the type of asbestos used almost exclusively for pipe covering in Germany at that time. This will have led to substantial exposure for workmen in many trades, and this paper describes the current epidemic of mesothelioma, which has followed after the usual prolonged latent period.

The first case was diagnosed in 1966; the patient was a man aged 39 , who, at the age of 15 , was apprenticed as an electrician in the shipyard for a period of three years and subsequently worked elsewhere as a clerk. Twenty-three years later he developed a persistent massive pleural effusion; the diagnosis was made only at thoracotomy, which was followed by the development of extensive tumour deposits in the thoracotomy scar. His case drew attention to the likelihood of a continued incidence, and to the importance of the differential diagnosis from other forms of thoracic malignancy. Over the following 10 years until June 1976, a total of 50 cases was diagnosed.
Since malignant mesothelioma was first described in relation to exposure to blue asbestos (crocidolite) in South Africa (Wagner et al., 1960) a high incidence of these tumours has been described in association with industrial asbestos exposure in Great Britain (Hourihane, 1964; Newhouse and Thompson, 1965), the United States (Selikoff et al., 1965), and elsewhere, and similarly in most British shipyards (Elmes and Wade, 1965; Sheers and Templeton, 1968; Ashcroft and Heppleston, 1970; McEwen et al., 1970; Whitwell and Rawcliffe, 1971). The literature has recently been reviewed by Elmes and Simpson (1976). N

The incidence of mesothelioma in relation to exposure to chrysotile in Canada (McDonald et 0 al., 1970) and to anthophyllite in Finland (Kivil- $\omega$ uoto and Meurman, 1970) is not greatly increased. F It is currently believed that the principal risk re- 0 lates to exposure to crocidolite, the use of which $\mathbb{D}$ has been very strictly controlled in the United Kingdom since 1970.

\section{Methods}

PATIENT SELECTION

Since the first patient was diagnosed in 1966, 
malignant mesothelioma was suspected in all patients with pleural effusions, even when there was no clear history of asbestos exposure. Investigations, therefore, included pleural needle biopsy, with either an Abrams' punch-biopsy needle or a fast rotating hollow biopsy drill driven by compressed air, as described by Steel and Winstanley (1969), together with examination of fluid cytology. Particular care was taken in recording the industrial history since leaving school.

It seems unlikely that many patients with malignant mesothelioma who were referred to hospital were not diagnosed. As a matter of policy the coroner was notified of any suspicious case at the time of death, and a necropsy was obtained; general practitioners were requested likewise to notify the death of any patient who had died at home.

\section{OCCUPATION}

Some degree of exposure is inevitable in the majority of trades involved in shipbuilding, as the dust has invariably been present from time to time in the relatively small enclosed spaces found inside a ship.

The occupations have been classified into those involving (1) continuous, (2) intermittent, and (3) varied exposure, based on the work of Sheers and Templeton (1968).

The distribution is shown in Table 1; it will be noted that only one subject was directly involved in a recognised asbestos hazard, namely, lagging.

\section{CLINICAL FEATURES}

The age at diagnosis ranged between 32 and 74 (average 60) years, the majority falling into the fifth, sixth, and seventh decades (Figure). Thirtysix of the 44 subjects, whose smoking habits were known, were smokers.

Table 1 Mesothelioma distribution

\begin{tabular}{llll}
\hline Exposure & Occupation & No. of patients \\
\hline Continuous & Joiner & 4 & \\
& Painter & 2 & \\
Intermittent & Lagger (pipe coverer) & 1 & 7 \\
& Electrician & 6 & \\
& Plumber & 5 & \\
& Driller & 6 & \\
& Engineer & 6 & \\
& Coppersmith & 5 & \\
& Housewife (plumber) & 1 & \\
& Shipwright & 1 & \\
& Caulker and burner & 1 & \\
& Welder & 1 & \\
Varied & Boilermaker & 1 & 34 \\
& Power station supervisor & 1 & 34 \\
None & Labourer & 6 & \\
& Engineer draughtsman & 1 & \\
& Housewife & 1 & 8 \\
& Housewife & 1 & 1 \\
\hline
\end{tabular}

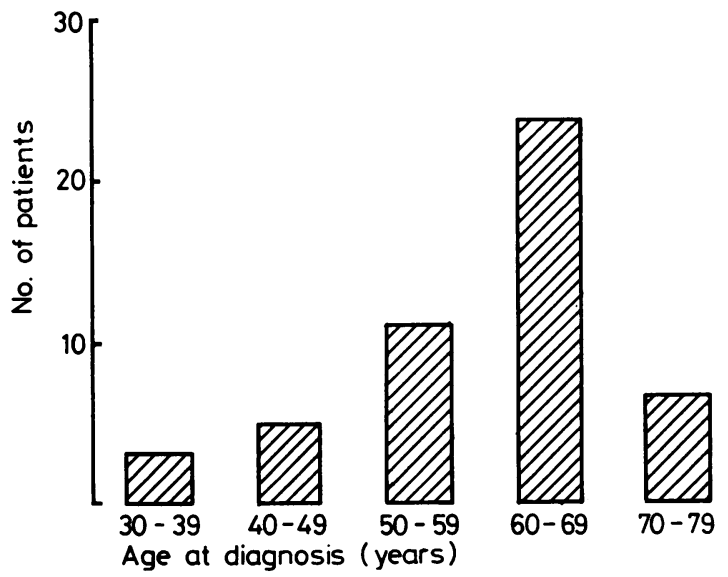

Figure Age distribution of 50 mesothelioma patients.

The incidence per year is shown in Table 2 . Since the study was completed in June 1976, five more cases occurred during the latter half of 1976 and six cases in the first half of 1977.

The interval between first exposure to asbestos and the diagnosis of mesothelioma varied from 20 to 62 years, with an average of 42 years.

\section{COURSE}

The initial symptom was invariably dyspnoea on effort, usually due to a massive effusion, resulting in many cases in displacement of the mediastinum to the opposite side in the initial stages. Effusions usually had to be aspirated initially at frequent intervals (one to four weeks), but the need tended to decrease since the effusion diminishes spontaneously with the passage of time. The general condition of the patient was frequently remarkably well maintained until the dyspnoea was replaced by pain as the chest wall was invaded by the tumour; loss of weight and deterioration in the general condition tended to proceed rapidly from this time. Because of the tendency for the fluid to absorb spontaneously, no attempt at treatment by instillation of cytoxic drugs or radioactive substances into the pleura has been made.

The average survival from diagnosis to death was only six months (range 1-37 months), and from the first symptom to death 14 months (range 2-95 months). Because of this very short survival time treatment with opiates presented no problems of addiction and the majority of patients required treatment with these drugs for control of their pain.

An enquiry made to the local office of the Department of Health and Social Security produced the information that only 21 of these 
Table 2 Incidence of new cases of mesothelioma 1966-76

\begin{tabular}{lllllllllllll}
\hline & 1966 & 1967 & 1968 & 1969 & 1970 & 1971 & 1972 & 1973 & 1974 & 1975 & $\begin{array}{l}\text { Jan.-June } \\
1976\end{array}$ \\
\hline No. of new cases & 1 & 2 & 3 & 8 & 7 & 4 & 7 & 2 & 9 & 2 & 5 & $\frac{0}{\bar{O}}$ \\
\hline
\end{tabular}

patients, or their widows, were then receiving compensation. Unfortunately the office concerned was unable to provide us with any further information, which we had hoped might help to explain this low figure. We believe it would be explained only in part by administrative delay. All patients or their relatives were advised on diagnosis that the disease is eligible for industrial compensation, and instructions as to how to apply were reinforced by the medical social worker.

\section{Results of pathological investigations}

\section{HISTOLOGICAL DIAGNOSIS}

The histological diagnosis was accepted by the Pneumoconiosis Panel of examiners in all cases, pleural biopsy proving successful in 30 patients during life. The diagnosis was made at thoracotomy in five patients and invariably led to spread of the tumour into the wound; the consequent increase in pain and distress was such that this method should in no circumstances be employed. In 15 cases the diagnosis was made only at necropsy, but in four of these the fluid cytology was positive before death. An acceptable diagnosis was thus achieved in life in 39 of the 50 patients.

The histological picture was predominantly mixed in 24 , tubopapillary in 15 , and undifferentiated (sarcomatous) in 11 cases.

\section{FLUID CYTOLOGY AND NEEDLE BIOPSY}

In the last 26 consecutive patients, pleural fluid has been examined for cytology by Dr. E. Blanche Butler, the results being compared with the pleural biopsy specimen.

In 16 subjects both fluid cytology and needle biopsy were positive, in three the biopsy was positive but the fluid cytology was negative, in four the fluid was positive but the biopsy was negative, and in three both examinations were negative.

\section{ASBESTOS FIBRE CONTENT OF LUNGS}

In the last 20 consecutive cases the lungs have been examined for asbestos fibre content by Dr. F. Whitwell, using the maceration technique described by Ashcroft and Heppleston (1973). In nine subjects the fibre count ranged from 35000 to one million, and in nine more from one million to 35.4 million fibres per gram of dried lung tissue.
Only two cases showed fibre counts of less than 20000 per gram, which is an acceptable level for $\stackrel{\omega}{\circ}$ a population not industrially exposed to asbestos $\stackrel{\vec{\gamma}}{\rightleftharpoons}$ (Whitwell et al., 1977).

The lungs of 16 of these 20 cases were also examined for asbestos bodies. Only 10 were posi- $\vec{\sim}$ tive on section, but 13 of the 16 showed asbestos $\odot$ bodies in expressed lung juice smears.

\section{ELECTRONMICROSCOPY}

One centimetre cubes of lung tissue from a 은 standardised site in the right lower lobe posteriorly were taken at necropsy from a series of $30^{-}$ patients, 10 of whom had died of mesothelioma $\vec{\varphi}$ early in the current series (these subjects do not $\infty$ overlap with those examined later for fibre content after maceration); 10 had pleural plaques but had died from unrelated diseases; and $10 \stackrel{亏}{\circ}$ showed neither plaques nor thoracic malignant disease and served as controls. The specimens $\stackrel{\mathbb{D}}{\mathbb{2}}$ were examined, without knowledge of the source $\overrightarrow{\vec{P}}$ of the material, by Dr. F.Pooley, using an electron $\frac{0}{3}$ microscope microprobe analyser.

The number of fibres present were consistently small compared with those usual in pulmonary asbestosis. Five of the mesothelioma patients and six of those with plaques showed amphibole $\underset{\Upsilon}{\mathbb{N}}$ asbestos in small amounts, all save one being $\frac{x}{0}$ crocidolite: two of the controls contained croci- 3 dolite, and two chrysotile. No fibre was identified in the remaining specimens.

\section{ASSOCIATED PLEURAL AND PULMONARY LESIONS}

Forty-seven of the 50 subjects presented with a massive pleural effusion, which was grossly haemorrhagic in only seven instances. Pulmonary o fibrosis was not found clinically or radiologically $N$ but was present on microscopy of the lungs at $\stackrel{\mathrm{N}}{\mathrm{N}}$ necropsy in six cases.

Pleural plaques were diagnosed radiologically on the opposite side from the tumour in $30 \stackrel{0}{=}$ patients (fibrous in 20 , calcified in 7 , mixed in 3 ). $\stackrel{\$}{\oplus}$ At necropsy they were present in 26 of the 47. subjects, were stated to be absent in 10 , and were 0 not commented on in 11 .

\section{METASTASES}

Distal metastases were not recognised clinically in any patient but were not infrequently seen on the

\section{.}


chest radiographs in the opposite lung and hilar nodes. At necropsy, however, widespread metastases were found in 25 of the 47 patients examined (Table 3).

Table 3 Metastases in 25 out of 47 necropsy cases

\begin{tabular}{ll}
\hline Site & Number \\
\hline Opposite lung and pleura & 10 \\
Peritoneum & 8 \\
Liver & 7 \\
Hilar nodes & 6 \\
Kidney & 4 \\
Adrenal & 3 \\
Spleen & 2 \\
Mesentery & 2 \\
\hline
\end{tabular}

3 patients still alive

Apart from blood- or lymph-borne metastases, direct spread of the tumour occurred frequently to the pericardium, mediastinum, and the opposite pleura (10 patients), and through the diaphragm to the peritoneum (8 patients). One of the latter had very extensive, and possibly primary, peritoneal involvement, which may have extended upwards to the pleura.

Metastases occurred a little more frequently from those of mixed histology (14 of 23 cases) than from tubopapillary (6 of 14 cases) or undifferentiated (5 of 10 cases) tumours.

\section{Discussion}

Malignant mesothelioma may follow relatively low and sometimes brief exposure to asbestos dust. The heavy exposure, which occurred principally in the textile industry before measures for control of dust were introduced in 1933 (Statutory Rules and Orders 1931), frequently led to pulmonary fibrosis and early deaths from pulmonary failure or cor pulmonale heart disease. Thus death commonly occurred before the latent period for the development of mesothelioma had elapsed, a situation which does not apply in the shipbuilding industry, where exposure tends to be light and intermittent so that pulmonary asbestosis is relatively uncommon. The overall experience of mesothelioma in the Barrow shipbuilding industry is comparable with that in other shipyards, occurring in a wide range of occupations not primarily related to the use of asbestos, and several decades after the initial exposure.

The pathological evidence from this study confirms the presence of excessive amounts of fibre in the majority of lungs examined quantitively, using a maceration technique, compared with the levels found in the non-exposed population, but not with those in subjects with pulmonary asbestosis.

Electron microscopic identification of the type of fibre present in a series of 30 necropsies (10 with mesothelioma from the early part of this series, 10 with pleural plaques, 10 normal controls) showed chrysotile in only two instances, both normal controls, and confirmed that crocidolite was the commonest fibre associated both with mesothelioma and pleural plaque formation. No fibre was found in about half the specimens studied, probably due to the small volume of lung examined, and when the fibre was present it was small in amount compared with cases of pulmonary asbestosis studied by the identical technique. At the present time, facilities for electron microscopic diagnosis and typing of fibre in pathological material, as described by Pooley $(1975,1976)$, are severely limited, and require to be expanded if a fuller understanding is to be achieved of which type of fibre is safe and which dangerous and, indeed, which type is retained in the lung after inhalation, and which is cleared. In this connection it is of interest that Pooley (1976) found that the lungs of a group of Canadian miners, in spite of the fact that their work involved exposure to pure chrysotile, contained mainly amphibole asbestos.

In the meantime more information as to the type and amount of asbestos used in the industry should be made available. The incidence of new cases of mesothelioma continues undiminished, 11 more patients having been diagnosed in the 12 months since the series was closed in June 1976, an average of about one case per month in a work force of only 7000. Because of the long latent period, there appears to be little prospect of a reduction until some $\mathbf{4 0}$ years after the use of crocidolite is finally discontinued.

The frequent occurrence of metastases is broadly in accordance with the findings of Roberts (1976). In contrast with reported experience in the United States (Selikoff et al., 1965), in Canada (McDonald et al., 1970), and in the United Kingdom (Newhouse and Thompson, 1965; McEwen et al., 1970; Ashcroft and Hepplestón, 1970), we recognised no definite cases of primary peritoneal mesothelioma, although in one instance both pleura and peritoneum were extensively involved in tumour, and it was impossible to say where it had originated.

There is no convincing evidence that any form of treatment prolongs life, but the importance of early diagnosis must be emphasised as an essential step if effective therapeutic trials are to be carried 
out in the future. To this end, cytological examination of pleural fluid, especially in the early stages of the illness, has proved as useful as needle biopsy in this series, and involves the least inconvenience to the patient.

We thank Drs J. E. Horrocks and D. Stansfield who carried out the necropsies; Dr F. Whitwell for his detailed pathological reports and fibre counts; Dr E. Blanche Butler for the fluid cytology examinations; and Dr F. D. Pooley for the electron microscopic analyses. Drs A. P. B. Waind and $H$. M. Palmer each kindly referred several patients admitted under their care.

This study has been supported by financial grants from the Northern Regional Health Authority and from the former Manchester Regional Hospital Board.

We are grateful to Mrs V. Somervell for secretarial help.

\section{References}

Ashcroft, T., and Heppleston, A. G. (1970). Mesothelioma and asbestos on Tyneside. A pathological and social study. In Pneumoconiosis. Proceedings of the Third International Conference (1969), edited by H. A. Shapiro, pp. 177-179. Oxford University Press, Cape Town.

Ashcroft, T., and Heppleston, A. G. (1973). The optical and electron microscopic determination of pulmonary asbestos fibre concentration and its relation to the human pathological reaction. Journal of Clinical Pathology, 26, 224-234.

Elmes, P. C., and Simpson, M. J. C. (1976). The clinical aspects of mesothelioma. Quarterly Journal of Medicine, 45, 427-449.

Elmes, P. C., and Wade, O. L. (1965). Relationship between exposure to asbestos and pleural malignancy in Belfast. Annals of the New York Academy of Sciences, 132, 549-557.

Hourihane, D. O'B. (1964). The pathology of mesotheliomata and an analysis of their association with asbestos exposure. Thorax, 19, 268-278.

Kiviluoto, R., and Meurman, L. (1970). Results of asbestos exposure in Finland. In Pneumoconiosis. Proceedings of the Third International Conference, Johannesburg, 1969, edited by H. A. Shapiro, pp. 190-191. Oxford University Press, Capetown.

McDonald, A. D., Harper, A., El Attar, O. A., and McDonald, J. C. (1970). Epidemiology of primary malignant pleural mesothelial tumours in Canada. In Pneumoconiosis. Proceedings of the Third International Conference, Johannesburg, 1969, edited by 흘 H. A. Shapiro, pp. 197-200. Oxford University $\frac{\mathrm{c}}{\frac{\mathrm{c}}{7}}$ Press, Capetown.

McEwen, J., Finlayson, A., Mair, A., and Gibson, A. A. M. (1970). Mesothelioma in Scotland. क British Medical Journal, 4, 575-578.

Newhouse, M. L., and Thompson, H. (1965). Mesothelioma of the pleura and peritoneum following $\vec{\omega}$ exposure to asbestos in the London area. British Journal of Industrial Medicine, 22, 261-269.

Pooley, F. D. (1975). The identification of asbestos dust with an electron microscope microprobe analyser. Annals of Occupational Hygiene, 18, 181186.

Pooley, F. D. (1976). An examination of the fibrous 의 mineral content of asbestos lung tissue from the Canadian chrysotile mining industry. Environmental $T$ Research, 12, 281-298.

Roberts, G. H. (1976). Distant visceral metastases in pleural mesothelioma. British Journal of Diseases of the Chest, 70, 246-250.

Selikoff, I. J., Churg, J., and Hammond, E. C. (1965). Relation between exposure to asbestos and meso- 9 thelioma. New England Journal of Medicine, 272, $560-565$.

Sheers, G., and Templeton, A. R. (1968). Effects of asbestos in dockyard workers. British Medical Journal, 3, 574-579.

Statutory Rules and Orders (1931) No. 1140, Asbestos Industry Regulations. HMSO, London.

Steel, S. J., and Winstanley, D. P. (1969). Trephine 3 biopsy of the lung and pleura. Thorax, 24, 576584.

Wagner, J. C., Sleggs, C. A., and Marchand, P. (1960). Diffuse pleural mesothelioma and asbestos exposure in the North Western Cape Province. British Journal of Industrial Medicine, 17, 260-270.

Whitwell, F., and Rawcliffe, R. M. (1971). Diffuse malignant pleural mesothelioma and asbestos exposure. Thorax, 26, 6-22.

Whitwell, F., Scott, J., and Grimshaw, M. (1977). Relationship between occupations and asbestos-fibre $ᄋ$ content of the lungs in patients with pleural mesothelioma, lung cancer, and other diseases. Thorax, 32, 377-386.

Requests for reprints to: $\mathrm{Dr}$ J. R. Edge. North $\omega$ Lonsdale Hospital, Barrow-in-Furness, Cumbria? LA14 2JD, UK. 